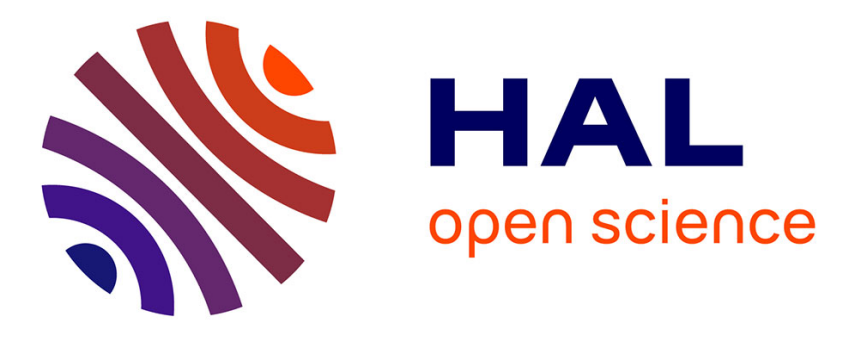

\title{
The use of prosodic parameters in automatic speech recognition
}

Jacqueline Vaissière

\section{To cite this version:}

Jacqueline Vaissière. The use of prosodic parameters in automatic speech recognition. H. Niemann $\&$ al. Recent advances in speech understanding and dialog systems, Springer Verlag, pp.71-99, 1988, NATO ASI Series. halshs-00363982

\section{HAL Id: halshs-00363982 https://shs.hal.science/halshs-00363982}

Submitted on 24 Feb 2009

HAL is a multi-disciplinary open access archive for the deposit and dissemination of scientific research documents, whether they are published or not. The documents may come from teaching and research institutions in France or abroad, or from public or private research centers.
L'archive ouverte pluridisciplinaire HAL, est destinée au dépôt et à la diffusion de documents scientifiques de niveau recherche, publiés ou non, émanant des établissements d'enseignement et de recherche français ou étrangers, des laboratoires publics ou privés. 


\section{J. Valseidre}

Contze National d'ztudes das T6locommunications 22301 Lannion, France

\section{ramords.}

prosody/ suprasegmental/ automatic speech recognition/ stress/ boundaries/ junctures/ segmentation/ phrase/ sentence type

\section{Aasmacr.}

The present communtcation concerns the use of prosodic parameters in automatic speech recognition (ASR), i.e. the feasibility of automatically extracting prosodic information from a set of acoustic measurements done on the signal, and the incidence of integrating such information on the performance of $A S R$. Prosodic parameters include pauses and contrasts in pitch, duration and intensity between successive segments (mainly the vocalic parts). This notion is also extended to number of syllables and to ratios of volced to unvolced portions of the words. Part one introduces the various aspects of prosody (linguistic and non lingulstic) and the main problems to be solved in automatically extracting linguistic messages conveyed by prosodic features. Part two deals with word level and lexical search: it presents work done (1) on the feasibility of word stress detection (primary stress, estimation of its magnitude, and evaluation of the complete vord stress pattern) and (2) on the estimation of the amount of lexical constraints imposed by stress information in lexical search, completed by other suprasegmental information (number of syllables, word boundaries, ratios between volced and unvoiced portion in the word, etc.). Part three deals With phrase and sentance level and syntactic constraints provided by the automatic detection of word, phrase and sentence boundaries. part four relates a number of miscellaneous uses at the phonemic level: phonetic segmentation, Identification of the volcing feature of consonants, and estimation of the "segmental quality" of the underlying segments.

It 1 observed that prosodic parameters have been exploited cather poorly compared to segmental aspects of speech. Integration of prosodic knowledge with segmental knowledge in an ASR system is a difflcult problem: to know when and where to integrate the prosodic knowledge into the system and how to combine the evidence and scores obtained from different sources. The exact contribution of the use of prosody in $A S R$ is still to be estimated in an ASR system flexible enough to efficientiy test such an integration. 


\section{Inrzoopoctran}

In the carly seventies there were number of papers directed to specialists of automatic speech recognition (ASR), written by wayne Lea [LEA 73a, 73b], pointing out the many poseible uses of the prosodic parameters. As eaxly as 1960 Lleberman showed that it is pos-ible to automatically determine the stress pattern of bisyllabic words uttered in 1solation with only 1 percent error [LIE 60). As Lea suggested, prosodic paraneters can be used at all levels in the decoding process of an ASR system: for example, at the aocustiophonetic level to separate volced from unvoiced stops, at the lexianl level to detect word stress position, at the eyntactic level to locate the principal phonological boundaries in sentences, and at the prapmatio lewal by locating the emphesized portion(s) of the discourse. Lea even suggested a prosodically guided speech underetanding system and discussed some of the alternative strategies for using prosodics to ald speech recognition [LEA 75b].

Presently, desplte the growing number of articles dovoted to that subject in recent years, the effective use of prosody in ASR 1s rather limited. In particular, a number of papers have calculated the theoretical advantages of adding prosodic information to ASR systems, to restrict the lexical search and speed up the process of word retrieval in very-large-lexicon ASR. Studies have shown that automatic detection of word stress and main functures in sentences 1. foaslble with a vary low error rate. The results obtalned in terms of improvement of porformance in ASR remain in most cases inconclusive for the following reasons: in some studies the process of extracting the basic prosodic parameters is not completely automatic, and automation is a necessary prerequisite for integration into an ASR syster, at least in bottom-up systens; in others. the decision algorithm are manually run. More 1mportantly, the value of integrating prosodically delivered information into otrictly spectral information in isolated words and in continuous speech has not yot been tested in an ASR syetem flexible enough to combine different types of information and to run systematic tests.

However, it seems obvious that the use of all the information that can be automatically extracted from speech signals (including prosodic information) is necessary to achleve progrese, particularly to ease the heavy constraints imposed by the existing recognizers: linited vocabulary size, restricted syntax, necessity to adapt the system to every new speaker, or obligation of the speaker to Insert - pause between overy word in the sentence.

As sollcited by the organizer of this course, the purpose of this contribution is to provide a general survey of the use of prosodic knowledge in ASR. The first part includes introductory remarks on prosody which are relevant to the use of prosody in ASR. It alms at meeting the needs of readers wishing to quickly up to date about the state-of-the-art in this domin. The following parts provide survey of the work alreedy done in the fleld In English, French, Swed1sh, Italian and Japanese. Part two malniy concerns word lovel. specifically the detection of stress and the use of prosodic filtering in lexical search. Word level is the level at which most work has been done, particularly in the fleld of 1solated-word systems. part three deals with the detection of phopologteal boundarien in the continuum and part four sumarizes some other uses at the phonemic lovel.

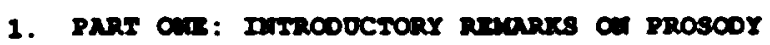

\subsection{The four besle enpecte of prosody}

In spoken sentence, the successive sounds (vowals and consonants) vary in pitch, duration and intensity. Such variations are conditioned by a number of factore which axe reviewed succintiy in the following paragraph.

a) Phonotically conditionod sapects intrinsle ralues and coarticulation

Part of the observed variations in pitch, duration and intensity depend on sounds in sequence and are often called "phoneticallyconditioned aspects of prosodic parameters". These variations are conditioned by differences in the physlological mechanism involved in the production of each individual sound, on one hand, and by temporal, coarticulatory constraints due to the overlapping of articulatory gestures corresponding to phonemes in sequence, on the other hand. Lat us examplified briefly the two types of phoneticallyconditioned variations: intrinsic characteristics of the phonems and contextual modifications.

1) Intrinsic characteristics of the phonemse have been rather well investigated. In particular, duration, fundamental frequency (Fo) and intensity of the vowels are known to be correlated with tongue height. High vowels (such as $/ 1 /$ ), for example, have an intrinsically higher pitch, a shorter duration and an inherently lower intensity than low vowels (euch as /a/). Nasel vowels in French are intrinsically longer than oral vowels. Tense vowels in English are intrinsically long and lax vowels short. Duration of a vowel is therefore correleted with the degree of vowel openness in French and English, the feature oral/nasel in French and the feature tense/lax in Englioh.

2) The lumediate context also has an influence. Vowels in unvoiced consonantal context (such as /p-p/) have a relatively higher pitch and are shorter in duration than the same vowels in volced context (such as $/ \mathrm{b}-\mathrm{b} /$ ). The lnfluence of volcing on the duration of the preceding vowel is Increased when both the vowel and the following consonant belong to the same syllable. Duration of a vowel therefore depende on syllable boundary location and the voice-voiceless feature of the following consonant (See Lehiste 's book on suprasegmentals for an excellent review of phonetically- 
conditioned aspects of prosodic parameters, LEH 70). Such aspects are mainly speaker-independent and, to a great extent, independent of the language spoken. They may indirectly contribute to the identification of the underlying sounds, but do not have a linguistic function per se. In automatic decoding of prosodic information, it would be advantageous to normalize the prosodic parameters for such varlations (see details later), but this can only followed identiflcation of the underlying segments.

b) Iinguistic aspect of prosody: eyntex and rhythm

The part of variations in pitch, duration and intensity which is not conditioned by purely articulatory constraints is the carrier of linguistic messages. Those linguistically-motivated aspects of prosody are of utmost interest for automatic decoding of sentences. They carry information concerning individual linguistic unitg at various levels (on phonomes, but also on syllables, on word stress, accent and word boundaries, on phrase and sentence types and boundaries), on one hand, and concerning the acoustic etructuring of each unit into larger units (phonemes into a syllable, syllables into a prosodic word, prosodic words into a sentence), on the other hand. These linguistically conditioned aspects of prosodic parameters and the prosodic structuring of each spoken sentence which are, for alven language, speaker-independent also seom languageindependent to a certain extent (see VAI 83 for further references).

The basic problem is the following: prosodic paxameters are the same time governed by the syntactic-somantic organisation of the sentence (KLA 76), and also by xhythmic principles (LEH 80). There may be a substantial difference between the units as defined by syntactic-semantic constraints and the rhythmic units (FOW 77 ). As a consequence, both influences may become conflicting. syntactic influence results in varying duration and $F_{0}$ to contrast the units in sequence to mark boundaries. Rhythmic influences results in a tendency for the syllables and the stresses to eveceed at regular temporel intervals. The segments duration are compressed or expanded to preserve the globel duration of the successive syllables as invariant (isosyllabicity) and to equalize the time-interval between two stressed syliables (1sochrony). At the same time, they are shortened or lengthened to mark the syntactic-semantic organisation. The coexistence of the three types of influence, (phonetically-conditioned aspects, thythmic tendencies and syntactic-semantic organisation) is the main source of difficulties for interpreting the cause of atriking lengthening or shortening phonemenon (at the level of a syllable, a vowel on a consonant).

Rhythmic tendencies could be exploited in a predicting way, fo gaining information, for example, on syllable boundaries (Gerar Bailly, personal communication). The present use of prosody in AS mainly concerns its syntactic aspects, and exploits the constrasts in $F \circ$ and duration in a down-up tashion. One of the most interesting functions of prosody from an ASR point of view, is the grouping of semantically related words such as noun and an adjective preceding or following it into a single so-called prosodic word and to express different degrees of functures between successive prosodic words. Segmentation and structuring by prosody do not allow recovery of the complete syntactic structure of sentences in every day conversation. It may happen (1.e., when isolated sentences are pronounced in a neutral but careful way) that the prosodic structuring exactly maps out the syntactic structure, but in most cases There is not a one-to-one correspondance. In sentence like "The dog likes the amall cat", or "le chien aime le petit chat" (this tendency is language- independent), the maln (and only) boundary may be placed either after the subject noun phrase, or the verb. or there may be an equivalent boundary after the subject noun phrase and the verb. The adjective and the following noun are lileky to be grouped into a single prosodic group and no boundary is expected between these two lexical words.

A. a result, prosodic information decoded from the signal should be compatible with lexical hypotheses made by the lexical search and with hypotheses made on the sequence of words by the syntactic module. Because it is necessary to provide for possible inter- and intra-speaker variability, algorithms for compatibility checking at the lexical and syntactic levels (in a veriflcation process) are easier to conceive than algorithms for prediction (In a hypothetisation process).

o) Mon-21nguistic appets: spaker's foeling about what he saye

A sentence may also be uttered in a non-neutral, but more or less marked manner. The prosodic variations are then knowingly controlled by the speaker to eventually communicate knowledge about his attitude towards what he is saying: doubt, irony, involvement, conviction, etc... or to direct his listener's attention toward the moxe important words of his discourse. There is a continuum between completely neutral and marked manners of uttering a sentence. The acoustic corrolates of "doubt" or "1rony" marking are not yet well investigated, and, no need to say, the sentences to be prosodically decoded should be uttered in a rather neutral way (see the work done on automatic classification of Hailiday's tones superimposed to the words "yes", "no", "mmm" and "mell". AIN 87). The system has to be however flexible enough to handle certain amount of emphasis (such as the assignment of emphatic stress or focal accent to particular word(s) in the sentence). This aspect of prosody is particularly important in dielogae where the speaker tends to emphasize key words to clarify a question or an answer. 


\section{d) Paralinguletic aspects: physiological differences and dialect:}

Furthermore, deviations from comonly observed patterns may contribute to inform the listener(s) about the opoaker himself: pathological accent, foreign accent, emotional state, physical condition, etc... (Note that these are generally not under the control of the speaker).

The last two aspects (non-linguistic and paralinguistic) of prosody, which are speaker-dependent, moy obscure the linguistically conditioned aspects. None of the actual achievements have tackled the problem of automatic adaptation to the "abnormal" particularitles of a speaker. The existing systems expect speakers to differ very little from each other.

\subsection{Interactions on prosodtc parameters and normalisations}

a) A specielc function is carried on by a comblnation of all cues

As stated before, the colative contribution of phoneticallyconditioned variations and of each of the many functions of prosody to the determination of the observed quantitative values of the three physical variables (Fo, duration and energy) is not easily determined. One specific function (such as stress marking or juncture marking) is generally not defined by a single prosodic parameter but by a combination of all prosodic cues: duration, intensity and $F_{0}$ (and eventually by the insertion of a pause). Furthermore, the exact contribution of each parameter varies as a function of the context. Let us fllustrate the complexity of the phenomena.

In a stressed language (such as English or Italian), the phonologically atressed eyllable of a word tends to have a relatively longer duration, a higher (often rising) pitch and a greatex intensity than the surrounding unstressed syllables. These are only tendencies. The criterion of a longer duration may fail, and the cases of fallure are predictable.

First, the criterion of a longer duration may fall, In cases where the stressed vowel is an intrinsically short vowel (such as $/ I /$ in English) surrounded by intrinsically long vowels, and/or it belongs to a syllable with a lazger number of phonemes than the surrounding syllables (the larger the number of units at one linguistic level, the shorter the length of each unit), and/or it 1s located next to syllable which has been lengthened because it is a wordfinal or a phrase-final syllable, etc... the stressed vowel may be shorter than the surrounding vowels.

second, the criterion of a higher intenasty may also fail when intrinsically low intensity vowels (such as $/ I /$ and $/ I /$ ) are surrounded by inherently high intensity vowels (such as /a/). The criterion of a integrated inteneity over the vowel fails when the vowel is too short.
Third, the criterion of a highor To may fall. A pitch movement is often present on each stressed syllable. Depending on the position of the word in the phrase. Fo may be mainly rising or falling during the stressed syllable (When two words are regrouped into a single
prosodic word, there is a (language-independent) tendency for fo to rise during the first word and to fall during the second; see illustration laterl. An Fo rise, which is often concomitent to a stressed syllable, may also be found on an unstressed syllable (such as the realisation of a continuation rise on the final vowel before a non-final pause). There is also natural tendency for Fo values to rise at the beginning of sentence, then to decline (the so-called "declination line") and for the pltch range to diminish throughout the sentence: the relative height of the stressed syllables and the amplitude of the pitch movement are to be interpreted according to the position of the syllables in the sentence. The largest Fo movement s are expected near the beginning; if not, a word located elsewhere than at the sentence beginning is emphasized. The lowest Fo values are expected at the end of the utterance; if not, the sentence 18 marked (it might be an interrogative sentence).

There are three consequences: first, combination of at least three parameter (pitch, duration and intensity) is desirable to achleve more reliable decisions, even for isolated words; second, contextual rules are necessary to achieve rellable decisions in continuous speech; third, a prosodic event (such as a vowel lengthening or an Fo rise) will often recelve more than one interpretation.

b) Normalisation by articulatory and percoptual considerations

As expected, some algorithms attempt to substract the effect of phonetically-conditioned variations. Such normalisation requires identification of the sounds and possibly the position of syllable boundaries.

Ideally, compensation includes:

1. the Intrinsic characteristics of the phonemes and the influence of the surrounding phonemes.

2. the number of phonemes in the syllable, of syllables in the word, and of words in the sentence.

3. the speech rate:

4. the correction for prepausal lengthening.

Present systems only include partial compensation of the phonetically-conditioned varlations, 1.e. of the ones which are the easiest to integrate. It is not clear whether or not such partial normalisation is better than no compensation at all (there is no known comparative studies). Indeed, complete compensations can be carried out only in a verification process. Details on compensation in present systems are described in Part II. 
It has often been said (IEA 80C) that the raw data for prosodic decoding should not only be corrected for the phoneticallyconditioned aspects but should also take into account knowledge about specch porcoption. It is evident that such a "normalisation" by perceptual considerations should lead to a more integrated view of the relative contribution of the three basic prosodic parameters, duration, Fo and intensity. However, knowledge on how duration, Intensity and Fo are perceived and processed in continuous speech is not advanced onough to be applicable in an ASR system.

\subsection{The zole of prosody in speech docoding}

a) Is prosody used by humen liaterers?

It 1s often argued that ASR systems should parallel, to a certain extent, the way humans perceive speech to be successful. One may question the real use of prosodic parameters by human listeners.

Do listeners use prosodic cues at all? How do they use them and when? And how far do the prosodic cues contribute to the understanding of the whole message?

Despite the apparent complex manifestation of the organisation of prosodic parameters, listeners seem to have no difficulties in decoding prosodically-carried information, at least in controlled experiments. The effective use of prosodic parameters in every day conversation and its exact contribution to the complate decoding of sentences are rather difficult to test. Despite the fact that it is easy to invent pairs of sentences which can only be made unamblguous by a single prosodic event (the position of a functure or of a word stress), the cases where prosody cues are vital for comprehension of the message are rather rare in every day conversation. Because of that, prosodic aspects are often said to be redundant with spectral aspects, making the assumption that spectral aspects are sufficient for uniquely decoding the sentence. The assumption of redundancy may be questionned. It has been shown that 11steners pay attention to prosodic continuity at the expense of semantic continuity (DAR 75). Nevertheless overall intelligibility systematically declines with an increased degree of time-compression; sentences heard in normal intonation are significantly more capable of withstanding the debilitating effects of compression than those heard in anamalous Intonation (WIN 75). Understanding spech synthesis when there is no control of the prosodic parameters requires a particular effort from the listener. Deciphering a spectrogram without using temporal cues and Fo contour is much harder than using all cues avallable (personal experiment). It is equally reasonable to assume that not only the spectral aspects but also the temporal aspects and Fo are parallel inputs to the ears of the listener who simultaneousiy decodes them, and that a imultaneous treatment of both inputs might be absolutely necessary for automatic recognition of continuous speech. Such view is generally accepted in the psycho-linguistic literature. b) The particuler role of word atreas

The exact part played by word stress in continuous speech pro cessed by listeners is not clearly established. Nevertheless, number of studies have investigated the potential use of stressed. syllable detection in an ASR system. The arguments are the follow. ing :

- 1) the position of word stress is atrletly necoseary to the differentiation of words uttered in isolation. Some words such as noun/verb pair (PERmit-perMIT) are distinguished from each other almost entirely on the basic of stress position (in English or Italian, for example). (In languages with flxed word stress position like French, syllables found as "stressed" by prosodic considerations, 1.e. a longer duration and an higher Fo, may not only correspond to a phonological stress on the last word syllable, but also to emphasis at word onset].

- 2) in English stressed syllables seem to represent 1slande of roliablitity where the acoustic cues are relatively more robust. Experiments in spectrogram reading by experts and analysis of the phonetic confusions made by automatic acoustic-phonetic decoders confirm the fact that stressed vowels are more essily recognized than unstressed vowels (LEA 75a). Easier recognition is often explained by the fact that in word stress the syllables are lengthened. (Such an observation is compared to the notion of acoustic dominancy in French. In French, the "dominant" consonants, 1.e. consonants which are located in portions of the aentence where Fo is rising, have characteristics closer to the norm than the same consonants in other contexts (VAI 86). Note that phoneme dominancy is an acoustic notion and it 1s determined by the actual position of phonemes in the prosodic structuring of the sentence, while stress is a phonological notion].

- 3) a number of theorical studies have demonstrated the usefulness of stress detection for a miti-level sooses to the lexicon. It has been shown that stress pattern information can reduce the lexical search in English and Italian. For Inglieh, dividing phonemes in stressed syllables into broad phonetic categories (manner of articulation) while "wild-carding' the unstressed syllables is almost as restrictive as representing the vocabulary by six broad phonetic classes (HUT 81: ses also CAR 87). Stress information make thus restrictions that are potentially very useful for large-vocabulary, isolated-word speech recognition. Using a 15,000 word lexicon, and assuming a three level convention for the description of each syllable istressed, unstressed and reduced) and a single stressed syllable per word, Aull showed that knowledge of only the number of syllables of the word yields an expected class size equal to approximately 41 percent of the size of the lexicon. When the stress pattern is known li.e. the 
correct number of syllables and the correct assignment of stress for each syllable), the expected class size is reduced to 19 percent. If the number of ayllables is known as well as the location of the stressed syllable in the word, then the expected class size 18 22 percent [AUL 84]. The charateristics of lexical stress and their possible use in automatic speech recognition of the Italian language have been investigated at GSELT. A theoretical analyais of the constraints imposed by stross in the strategy of a large lexicon was conducted on the basis of 12,000 word vocabulary: knowledge of the number of syllables and the stress location potentially allows reduction of the cohort 120 to 1.3 percent of the entire lexicon [PIE B7].

\section{c) The basic function of alterning ro rises and falle}

Perhaps because a Fo rise is mainly realized by tensing the vocal folds and Fo fall by relaxing them, an upward change of Fo between two successive vowels seems to be associated with the notion of beginning and a downward movement with the notion of end in number of languages (see VAI 83 for references; see also AIN 86, IIN 83). As a first result, decrease in Fo usually occurs at the end of ach : major syntactic constituent and an increase in Fo occurs near the beginning of the following constituent (the so-called fall-rise pattern used as a boundary marker (disjuncture phenomena) ( $C O O$ 77, LEA 72, LEA 80). As a second result, rise and fall often appear as a pair, and thus the schematized Fo pattern exhibits a so-called hat-pattern (MAE 76 for English), used for word grouping (juncture phenomena). In English, Fo movements are 1 imited to the stressed syllables; in French, to word boundaries.

As noted before, there is more than one way to utter given sentence. There are four basic ways to structure prosodically the following declarative:

THE SA IXKS THE SJALL DQG.

THE CAM UKES THE SMALL DQG.

THE CXTLIES THE SSAIL DQG.

THE CAT LIKES THE SMALL DQG.

(the pattern are schematized according to Maeda's method; see MAE 76 for further examples). The number of rises and falls depends on speech rate. As noted before, the number of large Fo movements decreases as rate of speech increases. (1) is more likely to correspond to slow speech, and [4] to rapid speech. Due to rhythmic constraints, there is also a tendency for the long words to correspond to a complete pattern, and for short words to be regrouped into a single pattern: a boundary (marked by a fall-rise pattern) between the subject noun phrase and the verb is more likely to happen when the subject noun phrase is long (in terms of number of syllables). As a consequence, for given sentence and given rate of speech, a certain type of prosodic patterning is more likely to occur than the others. It is however necessary to integrate the possibility of differences between speakers into the system.

\section{d) Speaker-depandent variations}

The same basic principles govern the determination of the prosodic parameters for all speakers, but the relative contribution of phonetically-conditioned variations, stress, rhythm, syntax, semantic, style and rate is speaker-dependent. Each speaker tends to be consistent, but there are regular differences between speakers. The tudy of speaker-dependent regularities is very important for ASR: the tuning of the system to the particular habits of the speaker is a prerequisite for a full extraction of the information.

Lot us give some typical examples. I have compared the prosodic "habits" of two native speakers of English, JA and KNS, while reading long texts. The following represents the schematized Fo contours (schematisation is done using Maeda's method, MaE 76) for the flrst sentence of the first text (unpublished data). Only the Fo movement from the "plateau" to the "base-line" and vice-versa are schematized.

Schematized pattorns for speaker JA

THE ySSACHUSETTS INSTITUTE OF TECHNO

IS A COEDUCLTIONAL ITDEPENDENT INSTITLION,

WHOSE PRINCIPAL ATERESTS ARE NNGINEERING SCINCEY,

PURE SCXENCES AND ARGHTTEETURE

Schematized pattern for speaker kNS:

THE ASSACHUSETTS INSTITUTE OF TECHNOLdGY

IS A fOEDUCACIONAI FIDEPENDENT INSTITdTIO\%,

WHOSE PRTNOSRAL INTERESTS ARE ANGINEERINQ SCIENCES

PYNE-SCIENCES AND ARCHITECTURE 
There ar least four points for which the two speakers differ. There are at least four points for which the two speakers dimposed to 1) The ro tall for Ja are always rapid (that is superinposed to a single syllable) and concomitent to stressed syllable (primary or secondary) (excepted at sentence end, where the fall is superor secondary) imposed to the last sapid or gradual (see "coeducacontrast, for KNS, the falls are rapid or gradual (see meoeducational" In (10). "principal" in (11]). Rapid falls are superimposed either to atressed syllable or to a function word (a reguposed observed in the remaining parts of the texts).

- 2) For JA, there may be a fall in a stressed vowel, directly followed by a Fo rise marking continuation in the noxt (unstressed) ayluable (see "sciences", (3) and (4)). For XNS, when a continuation vord is used on the word's last syllable, the fall on the tion word ls used on the wo always suppressed (see "sciences" in [10] and (11]).

- 3) For JA, there was no lexical word without at least an Fo movement uperimosed on it, unless than it is uttered entirely in the ment superimposed on (1t, unless than (5]). For kNS, the lack of Fo upper ro regiater movement on a lexical word mark lex the following paragraph).

- 1) For JA, adjective and following nouns are always regrouped into 4) Por Ja rise during the first word and a fall - eingle prosody word during the last): "independant lnstitutelon " interest" in [7], "engineering sclences" In 17]. "pure sciences" in (8). etc... For KNS, adjective and following noun may be in $(8)$. regrouped In the same way ast cases, there is a rise in the dent lnstitution lo be no $F$ first word, followed by:
movement on the last word.

Such speaker differences are very important to grasp by rules. Such such apeaker differenciste for all use of prosodic information in rules are prerequisite more work in that direction (there 18 no ASR. There is need of modeliting intra- and extra-speaker differknown syses).

\section{e) The use of pauses as boundary marker}

The acoustic analysis of speech shows that speakers insert a large The acouste analyelos opresent only number of pauses while talking. Mapplratory paunes reper part of all pauses; there axe also hosltation pauses , but the mafority of pauses (including the respiratory pauses) are located at majority or pases ase of pauses as major boundary markers gramitical junotures. sentences seem to be similar across those languages for which there is available data. f) The use of lengthening as boundary maxker

In a number of languages (English, German, French, Spanish, Itian, Russian and Swedish) there is a tendancy to lengthen the flnal elements in the linguistic structure, particularly the last vowel before a pause, as well as the final elements in words and phrases (see VAI 83 for references). It seems that lengthening, like Fo fall, is associated mainly with the notion of termination.

\subsection{Conclueton}

The preceding remarks on prosody are far from of being aufficient to introduce the complexity and richness of information carried by prosodic parameters. Articles concerning descriptive analysis of prosodic parameters corresponding to different speech stylss, to different speakers and to different dialects, automatic generation of prosodic parameters for automatic synthesis-by-rules program, the rapidly developping area of non-linear phonology, psycho-acoustic and psycho-linguistic studies on the perception of pitch, duration and intensity in continuous speech; the articles on automatic segmentation of speech and on fundamental frequency detection, etc.... may be of utmost importance to those interested in adding prosodic parameters to their system. The proceedings of a seminar devoted to the role of prosody in ASR may also be of some interest (DIC 82, in French).

In modelling prosody for integration into an ASR system, it is essential to keep in mind the following points:

- (1) the speaker is expected to speak in a more or less noutral way - (2) there is more than one neutral way to utter a single sentence although the number of ways is still limited;

- (3) the acoustic evidence of secondary marked junctures decreases as the mench rate increases: roughly speaking, the amount of prosodic information is inversely proportional to the number of syllables per second:

- (4) vocalic portions of the signal play a prominent part and are the main carrlers of temporal and Fo contrasts; however, contrasting eyllable duration and relative lengthening of consonants within a syllable are carriers of relevant information (wordinitial marking for example),

- (5) the binary diviaton between long and short vowels, or long and short syllables or stressed and unstressed syllables, often used to describe the perception of prosodic parameters is not entirely adequate in an ASR system; in continuous speech there is continuove variation in values,

- (6) Adaptation to tho spaker' partlcular patterns is very useful to fully extract the information contained in continuous speech; Without adaptation, less information can be extracted and finally 
- (7) there are some speaxer differences in the amount of prosodic 17) there are clgnal (at least manually information that can be decoded ences spoken by some speakers are using present knowledgel: sentences spoken brosodically than sentences spoken by others, independently of the speech rate;

The following sections describe specific work done in the field. a large number of papers more or less related to the uso of prosody in ASR in French and in English. Only those works where prosodic features are automatically extracted from speech signals prosodic features are automatically extracted As for the other languages (Swedish, Japanese, Italian), all papers known to the autor are cited (See also Noeth'es paper in the present volume, NOE 88 ).

2. PART TWO: STRESS DETECTION, STRESS MAONITUDE AND PROSODIC

\section{IIITERTING}

number of studies have been devoted to the role of stress in ASR systems. Despite differences, the systems follow approximately the same procedure. Thus the problem of detecting stressed syllables in isolated words or cont fnuous speech can be divided into five steps:

- 1) segmentation of the speech wave into syllable-like units,

- 2) extraction of the prosodic features.

- 3) normalisation of the features.

- 4) detection of stressed syllables and

- 5) testing the effectiveness of the delivered information in a complete ASR system.

2.1 Syllabic nuclal datection

As noted before, most programs start by detecting the syllabic nucleus to locate the vocalic portions of the signal. A typlcal program of that kind, written by Mermelstein, can detect over 92 program of that kind, written by Mermelsteln, can detect over percent of the syllabic nuclei. The program uses a spectrallythe requency range 500 to $4000 \mathrm{~Hz}$ ) to compensate for different intringio energies in various vowels, and an interactive application int "hull function" to first detect large energy dips then subdiof "hull function" to flips vide long segments between those big dips, by locating smaller dips within the chunks (MER 75). Segmentation can also be carried out by using the phonetic lattice produced by the acoustle-phon (see analyzer as in the French system, the article by Mercier al in the present book. MER 88) or the output of a broad classifier (such as in Aull's work). Interestingly enough, the segmentation errors are very similar, independently of the system used and of the language concerned. Segmentation is mainly based on abrupt discontinuity. Algorithms fail when segmental parameters are changing slowly over time. They fails often when two vowels or more are in sequence (vocallc linking) and when there two vowels or more are in sequence (vocallc linking) and when there $(/ 1 /$ and $/ \mathrm{r} /)$. The problem is particularly acute when the vowels have a low first formant.

\section{2 reatures deteotion}

Once the frontiers of the syllabic nuclei have been detected, the next step consists of calculating a certain number of parameters for each region (up to five, depending on the system). The calculated parameters are the following:

- 1) the duration of the sonorant portion of the segment or the duration between syllable boundaries defined by the onset of the sonorants of consecutive syllables (WAI 86);

- 2) the onorgy Integral (average of energy level over the vowel):

- 3) the fundamental fxequency, generally the pitch maximum [AUL 84 WAI 86]

- 4) a measure of spectral change for English (AUL, 84; WAI 86);

2.3 Hormalleation of the features

A number of normalisations of the raw parameters can be made. Some of the systems include:

- 1) compensation for the Intrinale characteristic of the vowels: The average energy level is multiplied by correction factor depending on the intrinsic intensity of the vowel when the vowel is identified (carried out by the acoustic-phonetic decoder or found in a dictionary when the word 13 known); in case the detalled identity of the vovel is not known, duration and pitch of the vowels are modified depending on an estimation of the first formant of the vowel (NIS 82; MEL 82) and the evidence of nasality (MEL 82). The values for the correction factors are of ten taken from LEH 60 for English and from ROS 67 for French (the tendencles are language-1ndependent).

-2) compensation for the longthoning-bofore-voiclng phenomenon: Automatic detection of the voicing feature of the consonant following the vowel is relatively feasible, but andque correction factor is hardly adequate in continuous speech. The magnitude of the effect varies as a function of the tense-lax feature of the vowel, the nature of the following consonant (stop or fricative). the position of the word and syllable boundaries and the position of pauses (CRY 85).

3) correction for propausal lengthening.

Such a correction is currently used in isolated words where the position of the pause is known (note that in this case, the correction includes not only prepausal lengthening but also the combined effect of word final lengthening): Dumuchel for example used fixed factor (DUM 86), while in Aull's algorithm, the correction factor is adjusted depending on the gross category of the final context (AUL 84). 
2.4 Algorithms for strese detection

2.4.1 Stress detection in 1solated words

a) The largest number of studies concerns stress detection for a) The largest num (cited in LEA 80) showed that while 72 perEnglish. Medress al (cited in LEA 80 ) showed that while 72 perhigher peak energy lévels, 70 percent and 68 percent could be detected from syllable nuclous durations and Fo peaks, respectively. Cheung t al (CHE 77) presents an automatic method which estimates the manitude of syllabic stress on a continuous scale in continuous speech using composite of three acoustic parameters: Fo intensity and duration. Results showed that perceptual stress corre lates highest with $F O(r=0.683)$, then intensity $(x=0.495)$ and lastly duration $(x-0.306)$ and that a combination of the three cues providas close approximation of the perceptual data $(r-0.876)$. In Aull's training date ( 350 words, 7 speakers), the most stressed syllable has the longest duration 65 percent of the time, the maximum amoun of energy 84 percent of the time, and the maximum in Fo 76 percent of the time. Aull made two Interesting observations: first, by reducing the duration of the final syllable to account for prepausal lengthening the maximally stressed syllable has the longest duration 90 percent of the time; second, the measurements were nearly as effective in separating stressed syllables from unstressed cyllables if onorants adjacent to the vowels were also included. The latter observation is important in automatic stress determination since it is often difflcult to separate sonorants from adjacent vowels automatically (AUL 84). In Aull's final system for recognizing lexical tress patterns from speech signals, duration (compensated for prepausal lengthening), logarithms of the average energy measure in two frequency bands $(400-5000 \mathrm{~Hz} ; 1200-3300 \mathrm{~Hz})$, maximum Fo on the syllable, and a measure of spectral change are computed for each sonorant syllable. The assignment of stress is made on a relative comparison of the syllables. In her study of 1,600 lsolated words, Aull has shown that 98 percent of the primary stresses can be detected. For the remaining 2 percent that are mislabelled, nearly 40 percent of the labeling errors is due to the front-end processor. In 30 percent of the labeling errors, the stressed syllable is marked as an alternative cholce for stress. The correct number of syllables and the correct position of the stressed syllable were found in 90 percent of the cases. The entire stress pattern (number of syllables, position of the stressed syllable and correct labeling of the remaining syllables as unstressed or reduced) was estimated in 87 percent of the cases (AUL 84). Dumuchel (DUM 86) examined the contribution of stress information in a HMM-based large vocabulary recognition system. The duration of the vowel part (normalized for lengthening-before-voicing phenomena and for prepausal lengthening) and the average energy level of the vowel (normalized for intrinsic energy) were ued for estimating the probability of the correctness of the estimated stress pattern. After an initial training phase, test on a new word list yielded 95 percent correct detection of the syllable carrying the primary stress. During word recognition, the likelihood of each word derived from acoustic data is modified by the probability that the required lexical stress pattern is supported by observed data. The rank of the correct word in the word hypothesis list improves by an average of 0.3 word positions when using the stress information. Excluding the two thirde of the list where the correct word was already ranked first, the improvement amounts to an average of 0.9 word positions. Dumuchel's experiments showed a (minor) improvement in the average word position in an avy system by using stress information (DUM 86).

b) Some work has also be conducted for Itallan An Investigation into several thousands of words spoken by different speakers was made in order to extract the statistical properties of the main stress correlates in Italian. The results suggest that in Italian duration has the most importance for stress determination (after correction of prepausal lengthening, duration has a stress relevance of about 91 percent. PIE 87; see also KOR 87). By using durations of vowels, average log-energy of vowels, maximum Fo within vowels, and average spectral change (Euclidian distance between consecutive cepstral patterns), over 96 percent of stressed syllables are well detected in isolated words (PIE 87).

2.4.2 stress detection in continuous speech

The particular problems in stress detection for continuous sentences are the following: first, the word boundaries are not known. and it is not possible to compensate for word-final lengthening; second, the grammatical, rhythmic and pragmatic aspects of prosody interact with word prosody; third, the words are not equally emphasized and the lexically stressed syllable may be not heard as "stressed" by listeners.

a) Lea and Waibel have proposed algorithms for stress detection in continuous speech for Ingliah.

Lea (LEA 73a) has shown that 89 percent of the syllables heard by listeners as stressed in continuous speech can automatically detected. The procedure locates stressed syllables from an "archetype algorithm" that uses increases in Fo and energy integrals (with 21 percent false stress assignments). If durations of nuclei alone are used, 84 percent are located with 32 percent false alarms; by using Fo rise only, 77 percent are detected with 24 percent false alarms.

Malbel adopted a pattern-recognition approach to optimally combine intensity, duration, pitch and spectral changes into one minimumerror stressed syllable classifier. When a forced docision is imposed by setting a threshold at stress probability 0.5 , erxor 
rates of 7.791 to 14.85 percent missed stresses were obtained Waibel concludes that anplitude integrals are the strongest predic tors of English stress in continuous speech (WAI 86).

b) The automatic detectability of syllables heard by listeners as otressed seems to be imilar for English and for French. In a $11 \mathrm{~m}$ ited study, Martin (MAR 77) has shown that in rrench, ranking in continuous speech of the syllabic nuclei into decreasing integrated intensity 1 effective in 81 percent of cases in detecting syliables heard as stressed by a panel of listeners.

c) In applying the previously described GSElT' system to 51 Itallan sentences, over 95 percent of the stressed syllables are detected but also about 16 percent of false stress (PIE 86).

d) A joint research project shared by the Phonetic Inatitutes at the Unlversities of Lund and Stockholm, "Prosodic Parsing for swedleh Recognition" has just started. The algorithms that are beginning to corge are intrinsically more complex that the algorithmo developed for stressed languages like Englieh and Italian, simply because Swedish prosody seems to be of a more complex nature. In addition to the basic distinction between stressed and unstressed syllables, the primary stressed syllable is characterized by having one of two tonal accents: acute and grave. The Fo representation of initial functure bears atrong resemblance to that of an acute focal accent, while the representation of a tinal juncture resembles that of grave word accent. House ot al (HOU 87), however show a promising 81 percent correct detection rate for grave eccents.

\section{5 zaxical flltexing by ouprasegmentel patterns and prosodic owos}

There are very few known studies on lexical filtering estimating the real contribution of the introduction of prosodic information at the word level in an existing ASR.

a) In atudy by waibel (WAI 87) on Inglleh, the suprasegmental features exploited were temporal cues (syllable ratios, ratios of unvoliced segment durations to syllable durations, volced segment duxations), Intensity profiles and stress likelihoods. Using a multispeaker continuous-speech data base for evaluation, each suprasegmental feature is shown to hypothesize the correct word substantlally better than chance. All suprasegmental features were then combined and compared with a speaker-independent acoustic-phonet 10 word hypothesizer. After applying the suprasegmental information, the correct word ranked on average 25 th out of 252 words. The acoustle-phonetic knowledge alone yielded an average rank of 40 lout of 252) without the addition of suprasegmental information. After aprasegmental and phonet1c KSs were combined the average rank was reduced to 15 out of 252 . The results indicate that suprasegmental information indeed adds complementary information that substantialiy improves word hypothesization in speaker-independent continuous speech recognition.

b) One of my own studies (VAI 76, 82) has shown that about 60 percent of the lexical words in rxepol are marked by an Fo rise at their beglaning and 70 percent by an Fo fall at the end. Minety-aix cent of Fo falls occux on word-final syllables and never on wordinitial syllables. Ninety-six percent of Fo rises occur at wordboundary syllables, either the firet ayllable in the word (wordinitial rise) or the last syllable (a manifestation of continuation rlse on the word-final syllable). Taking into account the fact that an Fo rise can only happen on the lest or the first syllable in a word, the system was able to eliminate 33 percent of the word poselblitles (consisting of more than two syllables) proposed by the lexical module from apectral knowledge only, leading to an appreciable reduction of the syntactic load (VIV 77). Only rather long words were suppressed, but no correct word was eliminated.

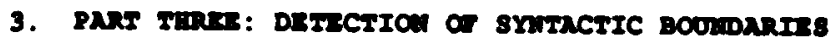

As seen before, prosodic knowledge provides a form of constraint on each word. Juncture phonemena (also called boundary phenomena) carry additional constraints on word sequonces. Whil stress detection concerns both isolated-words and continuous speech syetems, word- and phrase- boundary detection relates to continuous speech only. The basic prosodic features used for boundary detection are pauses, Fo typical movements and lengthening.

3.2 Pausea

O'Malley and his colleagues (OMA 73) have lead a study of the relationship between syntax and the position of pauses in spoken agebralo expressions. It was found that subjects were very con- 1stent in their placement of pauses when reading algebraic expresolons slowly. Furthermore, there was an slmost perfect correlation between measured silence and percelved juncture. Rules were developed for inserting parentheses based on the location and measured duration of silence intervals in an utterance. Ileteners were asked to insert parentheses given the spoken form, and the consistency of their answers was measured by a chi-square test. For those cases where there was listener agreeront in a single answer, the xules were tested and found to agree with the 2 isteners form 91 to 95 percent of the time.

In atudy, Len showed that 95 percent of the clauses and sentence boundaries are marked by a pause of 350 milliseconds or more (LEA 72).

3.2 To riene and talle

In one of his studies on cues to constituent structure and sentence boundaries in English, Lea (ish 72) showed that 94 percent of the syntactic boundaries of 500 sentences wexe marked by a Eall-ribe 
pattern in the pitch contour. He also noticed that sentence boundarles were always accompanied by fall-rise Fo contours. The program searches for substantial decreases $(7$ percent) in Fo followed by substantial increases, and marks a boundary at the last of the lowest Fo values in the valley. A computer program (LEA 73b) correctly detected over 80 percent of all syntactically predicted boundaries.

\subsection{Pauses and To movamente}

It is interesting to combine the information given by the position of pauses and the ro contour.

Komatsu and his colleagues (KOM 86 ) recently presented an algorithm for detecting boundaries between gramatical units and for formulating structural hypotheses in conversational speech (the task of a PBX telephone operatorl using Fo contour and the location of pauses. Pauses and Fo histogram are first used to detect sentence boundaries. Then, within a sentence, Fo contour is analyzed in detall by means of piecewise linear approximation with a sequence of linear lines. A number of solutions is proposed for each sentence. The preliminary results are encouraging. Their analysis relies on Fujlsaki's and co-workers' findings on Fo contours in Japanese. According to Fujisaki (FUJ 87), the Fo contour $1 \mathrm{~s}$ composed of accent components and phrase accents. There already exists a fairly detailed account of the interaction between both components, but there is no known attempt as yet to automatically detect word accents in Japanese.

\subsection{Lengthening}

Lea (LEA 75a) estimated how far phrase boundaries can be detected from measure of " phrace-Elnal lengthening phenomena". It was found that 91 percent of all phrase boundaries heard by listeners in spoken sentences can be detected by finding vowels and sonorant consonants that are at least 20 percent above the median lengths of the same vowel or sonorant in all its speech occurences. The duration of Interstress intervals tends to be short only when word boundary intervenes but increasingly longer for syntactically predicted boundaries between phrases, clauses and sentences. He also noted that the phonetic orror rate is more readily predictable from tho interstress interval than from other measures.

Phrase-final lengthening affects both the duration of the auccessive vowels and syllables. In a previous study, I compared the use of syllable duration (automatically detected). with the use of the vocalic part alone. There was no clear advantage of one method over the other. In 97 percent of the cases, syllables (or vowels) detected as long by the program corresponded to first or last syllable of a lexical word and to monosyllabic gramatical words (VAI 77).

\subsection{To movements and lengthening}

Combining To and duration information is necessary to improve recovering of prosodic information. By using both duration and Fo in each vowel and set of heuristic rules for detecting the main boundaries in sentences uttered without internal pauses in continuous French, program was able to detect main boundary in 86 percent of sentences (5 percent false alarms, most of them due to segmentation errors) (VAI 80 ).

Main boundary detection is probably the easiest to obtain automatically. To extract further information from duration and Fo contour and to determine clause, phrase and word boundarles, more complicated rules are necessary. PROSEIDON is an expert system developped for chunking the continuum into prosodic words IA prosodic word can contain one or several lexical words, preceded or not by grammatical words], for giving information about sentence type, position of the main boundary, left and right word boundaries and dominant and dowloated ayllables for a given sentence whenever possible. Connected to the acoustic-phonetic decoder (providing segmentation of the continuum into phoneme-size and syllablo-size segments), the prosodic module uses both down-up and bottom-up informations. In particular, the number of syllables and a measurement of speech rate determines the number of boundaries the module is expected to find (about one boundary for four syllables). The main boundary is first detected, and the continuum is chunked into two parts. Extra boundaries in the each part are detected then, taking into account the number and the position of the segment relatively to the main boundary and the surrounding pauses. Figure 1 illustrates the input data to the phonetic module. Visualisation of the parameters computed directly from the signal is important for the expert who elaborates the rules. A "prosodic transcription" of the sentence to be interpreted is done automatically from (1) Its temporal aspects (derived from calculation on relative length of the successive vocalic nuclei and syllables) and (2) its molodic aspects (dexived from calculation on Fo relative height between vocalic nucled and on Fo contour in lengthened vocalic parts). The principle on which the program is based is to Interpret concomitently the rhythmic (temporal) aspects and its melodic ( $F O$ ) aspects. In a preliminary experiment, the program was able to give an average of 2.8 pieces of prosodically extracted information per sentence and to segment the continuum into chunks containing an average of 1.3 lexical words with an error rate of 3 percent (VAI 84). For example, for the sentence displayed in Fig.1, the running of the prosodic program PROSEIDON delivered the following information: (1) declarative sentence, (2) main boundary (II) on the fifth syllable (In fact, the of fset of the subject noun phrase) and secondary boundary on the elgth syllable (the offset of the verb). The sentence was divided into three prosodic words (no error). The main weakness of the prosodic module is that it works in a top-down fashion starting calculation when the end of the 


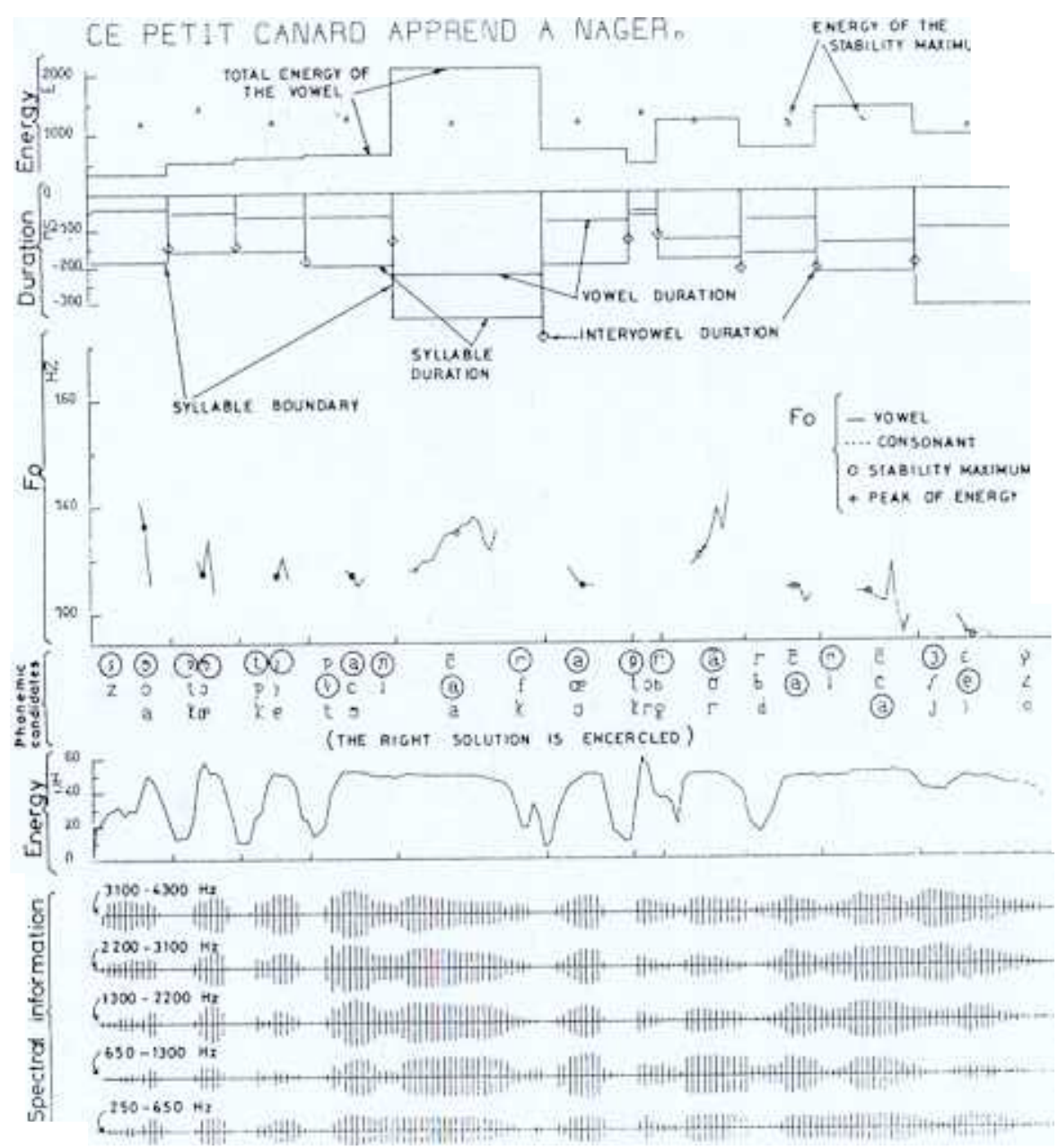

rigure 1: visualleation of the prosodle paramaters This figure shows one possible output for the sentence : " Ce petit

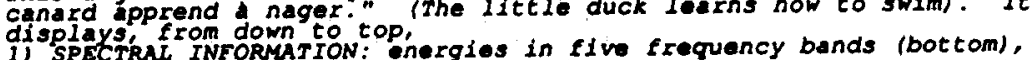
1) SPECTRAL INFORMATION: onergies in five frequency bands (bottom), 3) PHONEMIC CANDIDATES: the three IArst candidaces proposed by tho at the most st able part and the anpty circle the selocted value at

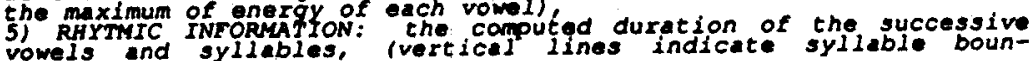
dariesl INSTTY INFORMATION: the Integrated energy over the vowel, sentence 1s reached. I am presently working on a new version of this program golng strictly from left to right in order to be useful in a real time application by chunking incoming speech into logical sense-groups.

3.6 Integration of the information bout boundariee in an asR

Allmost no work is done yet in that direction. An attempt has been made to use Fo-detected phrase boundaries to aid the syntactic parser in the BBN HWIM system (LEA BO). This procedure involved marking first all the words in the gramar that were expected to be Immediately preceded by Fo valleys (1.e., maln verbs, flrst stressed syllables in noun phrases, adverbs, etc.). Only about one sixth of the words generated by the gramar was expected to be preceded by Fo-detected boundaries. If a word was expected to be preceded by a boundary and a boundary was acoustically detected, then the priority or "score" for that word was increased substantially; if the expected boundary was not detected, the word's score is decreased. Onfortunately, while BBN implemented Lea's ideas in a version of their aHIM system, their profect terminated before any results were available. There is no attempt as yet to comrunicate the syntactic information dellvexed by PROSEIDON to KEAI' syntactic module.

As a consequence, it is not possible to conclude on the efficiency of integrating information on prosodic boundaries in automatic recognition of continuous speech.

4. PART FOUR: AID TO SEGMENATING AND ACODSTIC-PBONETIC DRCODINO

\section{1 sogmontation}

a) It is obvious that the error rate obtained by prosodic modules using duration as a parameter 1s very sensitive to segmentation errors. On the other hand, Vaissiere has proposed how the ro contour over the successive acoustic segments detected by the acoustic-phonetic analyzer of a ASR system can be used to estimate some cases of phoneme spreading and merging. For example, when a vowel is matched to a large ro rise (generally a manifestation of the so-called continuation rlea), it tends to be spread into two (or more) vocalle segments by the segmenter. In the verification process, If two contiguous but automatically segmented sonorant segments are superimposed on a continuously rising Fo contour, the two segments should correspond to a single phoneme (VAI 82b).

b) Bush (BUS 86) has examined the influence of durational constraints on recognition accuracy in an acoustic phonetically-based speaker-independent connected digit recognizer. The constraints are expressed using set of finite-state pronunciation networks, together with specifications of minimum and maximum allowable durations for network primitives. In particular, a set of networks incorporates additional paths representing prepausal lengthening for the digits "oh" and "oight". The recognizers were tested on corpus of 1232 5-digit and 7-digit strings with and without a priori 
knowledge of the string length. Recognition accuracies ranged from 33.9 percent to 94.6 percent and from 91.6 percent to 96.8 percent, for unknown and known string lengths, respectively, depending on the particular durational constraints incorporated in the network models.

4.2 Volood-roloolese distinction

Fo and timing of the events may be used to distinguish between voiced and unvoiced consonants.

a) In language like French, vibration of vocal cords during the entire or mafor portion of the consonent 18 the major cue distingulehing palrs of consonants like $/ p, b /, / t, d /, / k, g /$. The presence of To and the concomitent presence of low frequency energy are gen erally used in knowledge-based ASR systems for rrench lsuch as in the Keal system).

b) In a language like English, the presence of Fo is a weak cue for voleing (Fujimura, 1961). The shape of to at the vowel onset, just after the release, is a cue that has been proposed by Lea (Lea, jo73) to distinguish between unvoiced and volced consonants in ASR systems. The tining of the segmental events plays a preponderant part in distinction: rolos oneet time, closure duration and vorvel duration. How far such cues are used in the exlsting knowledgebased ASR system for English is unknown.

\subsection{Obstruent-non abetzuent distinction}

The To ehape during the rolood consonant is very useful in the visual decoding of utterances for which the spectrographic representation is supplemented by Fo contour, at least for French (personal oxperience). During the occlusion period of the vocal tract for the realisation of obstruent consonants such as for stops and fricatives, there is a concommitent drop in transglottal preseure which lomers Fo (FN 59). In other words, Fo 18 not expected to rise, nor to stay level during the realisation of the obstruent consonants. Moreover, the top and fricative consonants, at least in rrench and particularly when the consonants are in a dominant position, are typically accompanied by a typical Fo fall-rise pattern which does not exlet (or 18 much less marked) for non-obstruent consonants. Such characteristic is not yet used in present ASRs, but 1 s potentially useful for distinguishing between $/ \mathrm{m} /$ and $/ \mathrm{b} /$ or $/ \mathrm{v} /$, or $/ \mathrm{h} /$ and $/ d /$

\subsection{Domlsant-donlnated phosemen}

given phoneme is ideally realized with number of acoustic cuss. In actual speech, a number of cues may not be clearly present. Even a phonologically-stressed syllable may be acoustically dest ressed.

Ongoing research at CNET by Roland Vives and myeelf has shown the absolute necessity of prosodic consideration before performing detailed verification on phonetic hypotheses to dramatically reduce the number of fatal errors (1.e. wrong suppression of the right solution). After word matching by the lexical analyzer, verification of the presence or absence of such acoustic cues corresponding to each matched phoneme is carried out depending not only on the position of the phoneme in the hypothesized word, but also on the position of the detected phoneme in the actual prosodic structuring of the sentence. For example, an unvolced stop in a dominant position (the decision of dominancy is based on to and dusetion considerationsl has to be reallzed with the absence of low-frequency energy for a period of timo. In a dominated position, continued presence of low frequency energy is tolerated. The quantitative contribution of such prosodic considerations has not been systematically estimated since the work is far from being completed. The application of a first serles of verification rules using a combination of segmental, euprasegmental and lexical knowledges leads to suppressing of 45 percent of the lexicel hypotheses. Three percent of right candidates are suppreseed due to errors in segmentation and in Fo detection. Detailed verification of the ecoustic attributes of phonemes without prosodic consideration leads to numerous fatal errors, 1.e. the suppression of right candidates.

\section{3. comerobron noners}

It is not an easy task to come to a conclusion on the use of prosodic parameters in ASR. It is easy however to agree that very little has actually been done, that most studies are in fact prollmInary, and that most of the work 1s atill ahead. while prosody is potentially moxe ueeful in continuous speech recognition than isolated word recognition, less work has baen done in the former direction. The feasibility (a small percentage of errors) and usefulness of stress detection of 1solated words in ASR has already been rather well Investigated. In constrast, there is a noed for more research and experimentation in the domain of continuous speech and in dialogues. It has been shown that about elght out of ten syllables heard as stressed by 11eteners and most phonological boundaries axe atomatically detectable. Such information has not been however fully ueed. The state-of-the-art of the current ASR syetems does not allow easy integration of prosodic information. Prosody needs a tlexible host: it should be used both in a top-down and in a down-up fashion (for hypothetisation and verification), at ell levals (acoustic-phonetic decoding, lexicon, ayntax and pragmatics) and it requires feasibility of exchanging information between the different components of the recognizers.

The small amount of work done on prosody in ASR is by no means an Indication that prosody is not important. Prosody is undoubtedly a necessary component for successful recognition of continuous seech. Prosodic knowldege can assist us in solving uncertainties arising trom acoustic-phonetic orrors and ambigulties. If properly 
exploited, such constrainta could suggest promising hypotheses to pursue as well as eliminate unlikely intexpretations from considerapun. In more concrete terms, first, prosodic knowldege enables us to determine whether each word candidate has a prosodic profile compatible with the input ignals. In perticular, a prosodically otressed syllable should correspond to a "stressable" syllable as Indicated by the lexicon. Second, it allows testing to find whether a particular sequence of hypothesized words can occur within a prosodically correct sentence. Mord- and phrase- boundarles corresponding to hypothesized word sequence have to be compatible with the functure and disfuncture phenomena detected from prosodic analysis. Two prosodically-regrouped words should correspond to two syntactically closed rords. Conversely, detected major and minor boundaries should correspond to syntactic breaks. Third, prosodic knowldege provides a basis for predicting additional but unhypothesized fragment of sentences: a short, very low Fo frequency ayllable often corresponds to a function word. Prediction of the presence of a word category is very useful in certaln cases because it is often very difficult to hypothesise function words in a downup fashion, from segmental information only. Fourth, the relationship between "segmental" quality of phonemes and their position in the acoustic structuring of sentences seem to be very crucial in attributing the acoustic evidence to other sources of knowledge. Automatic identiflcation of phonemes in short, low Fo syllables should be given less weight. As described in this communication, there have been already some work in the former directions. Two other directions should be seriously investigated, concerning dialogue and gality control of incoming speech. First, sentence type (Interrogative, declarative, ...) and emphasis phenomene detected within the sentence should be plausible and appropriate in the context of an ongoing dialogue. Second, prosody is the only way to control overall "quality" of Incoming speech. Given the state-ofthe-art of the current recognizers a sentence has to be uttered in a particular way to be recognized automatically. The proposals to use prosody in "guiding" the manner of speaking based on estimated speech rate, range and distribution of Fo movements, and the use of natural tendencies to emphasize important portlons of the message (see VAI 86, PP 218) have nat yet been tested.

It is often said that prosody is complex, too complex for straightforward integration into an ASR system. Complex systems are indeed required for full use of prosodic information. Lea's and my own exper lments have elearly shown that it is not easy to integrate prosodic information into an already existing system such as HWIM or KEAL. It is necessary therefore to build an architecture flexible enough to test "on-line" integration of information arriving in parallel trom different knowledge sources, particularly from prosodic aspects of the sentence.
Maknoulodgemente

I wish to thank Shinfi Maeda, and Luc Mathan for kindly accopting to review a version of this paper, and perticularly Garard Bailly for his valuable suggestions.

Rerreveneces: (AIN 86) Ainsworth, W.A., (2986), "Pltch cahnge as cue to syllabification"

(AIN discrimination of "Aaifiday's primary tones", Proc. Of Institute of

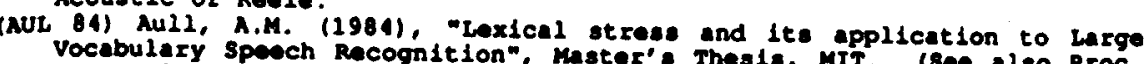
ICASSP-85, 14(9-1552).

(Bus 86) Dush, M.A., (1986), "Durational Contrainte tor Metwork-besed connected Digitel Rocognitilion". Proceedings of Mont real sork-based Con-

(CAR 82) Carbonell, N., Haton J.P. Lonchenty 21-22, 89-90. -Elaboration Experimente J.P. Lonchamp, F, E Plerrel, J.M.. (2902) sance; Application A $1^{\prime}$ Analyse symtexico-semintique dans lo syateMyrti1lo II", in (DIC 82).

(CAR 87) Carter, D. Boguraev \& Briecos, T., (1987), "Lexical stress and Phonatic Information: Which sogments or most Informativen, Proc. Cu (CHE 87) Cheung, $Y$. J. Apeech Technology, Edinburgh, Vol. 2 234-238. Stross Pattern. in Connect (1977). "Computer Recognition of Lingulat le ASsp, 252-258.

(COO 77) Coopex, H.x. \& Sorensen, J.M., (1977), "Fundumentel frepuency con-

(CRY O6) Crystal, syntact le boundaries", JASA, Vol. 62, No. 3, 683-692.

tional Cues", T.H. A House, A.s., (1986). "On the Avallibity of DuraMcolll University, Proceedings of Montreal symposium on Spoech Rocognition,

(DIC 82) DI Cristo, A. Haton J PROSODTE ET RECONANÁ́sSANCE AUTONÁTIQUE DE LA PAROLE, GAIF G." editors, (DAR 75) Derwin, Carlce, 289 Pp.

perception. C.J.e (1975), "On the dynanic use of prosody in speech PPEECH PERCEPTION. Hohen c Nooteboom, s. (eds), STRUCTURE NND PROCESS IN (DUM 86) Dumouchel, P. T Lenning, : Springer;

Lerge Vocabulery Speech Recognition (1986), "Using atress Information in Symosium on Speech Recognition, MeGill University, July 21-22, 75-76. (TNN 59) Fant, G.. (1959), "Acoustic Description and Classification of (TAR O6) Tertenati, Ericsion Technlcs, No. 1.

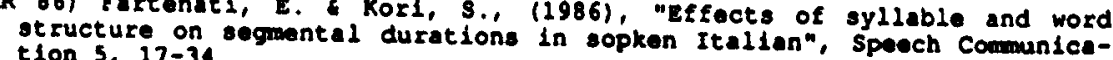

The rowler, C.A.. (1977), TIMING CONTROL IN SPEECh PROOUCTION, Ph.D. (FUS

Connected speech. E Kawai, H.' (2987) Reallzation of Word Accent in Connected speach in Japanese", Eleventh Internat 1onal Congress of (HOU 87) House, D., Bruce, G., Liecerde, Eatonia, U.8.8.R. Se 29.2. tomatic Prosodic Analyais for smedis and Llndblom, B.; (1997), "Au-

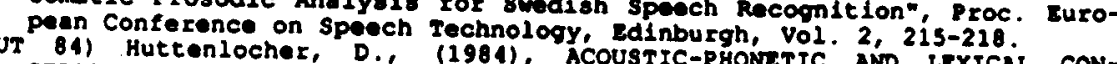

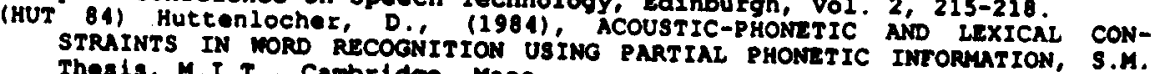
(KLA T6) Kiatt. D.H., (2976), Mase.

gliah: acoustic and percoptual ovidete uses of segmental duration in en(xom 96) Komater Ac and perceptual evidance", JASA 59, 1208-1221.

Conversational speech" ICAS8P "Prosodic Alds to structural Analysis of 87) Korl, S.. Farnotand, E. G Cosi P.

Rolevance and Application of Prosodic Inforome (1987). "A Perapective on Recogndtion in Itelian". Proc. European Confertion to Automitic Speech (IEA 72 , Edínburgh, Soptember 1987, Vol. 2, 211-214. 
able Location In Phonemic Recognitlon", B4th Meeting of the Acoustical 73al of Anerica, Miami, rlorida.

(1973), "Segmental and Suprasegmental Influences on Fundamental "requency Contours", in CONSONANT TYPES AND TONE, Souther (bingulatics No. l, k. Hyman editor.

(LEA 73b) Lea W.A., (1973), "An Approach to Syntactic Recognition Without Phonemics", IEE Trans. On Audio and Electroacoustics, Vol. AU-21, No
$3,249-238$.

75a) Lea, M., (1975), "Isochrony and Disfuncture as Aids to Syntactic Analysis". JASA, vol, S7, S33. cally Guided Śpeech Understanding strategy", IEeE Trana. Vol. Assp-23.

(LEA 80a) Lea, W., (1980), "Prosodic Alas to Speech Racognition", In (LEA (LeA g0b) Laa, w., (1980), "Speech Recognition: what is needed now?", in (LEA 80a), $562-569$

(LEA BOC) W. Lea (editor), TRENDS IN SPEECH RECOGNITION, Prentice Hall Inc (LEH 70 ) Iehiste, I . (1970), surrasegmentals, The MIT Press, Cambrdige,

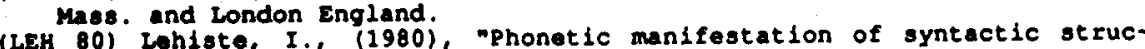
(LEH 80) Lahiste, I".' (1980), "Phonatic manifeat

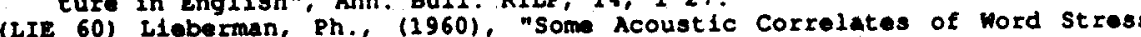
in Amorican Eng lish". JASA, Vol. 32, No. 4 (LIN 831 Lindsay, D., (1983), "A mothod of describing pitch phenomona" in
INVESTGATIONS OF THE SPEECH PROCESS (ed. Winkler), Bochun: Studienverlag Brockmayer, $189-210$

(MAE 76) Maoda, S.. (1976). A CHARACTERIzATION OF NMERICAN ENGLISH INTONATION, PhD.., M.T.T., DPt of Electro-Engineering.

(1979). "Automatic Location of Stressed Syllable in Erench", in Current Issues in Linguistic Theory, Vol. 9, P 1091-1094.

(MED 71) Medress, M.F.., Skinnax, T.E. And Anderson, D.E., (1971), "Acoust ic correlates of word stress", presented to the

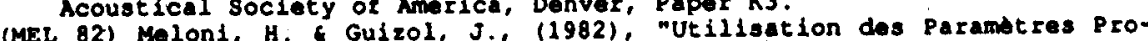

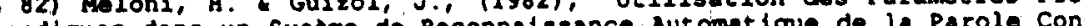
sodiques dans un syseme de

(MER 88) Marcler, G., Cozannet, A. C Vaissitere, J., (1988), "Recognition of speaker-dependent continuous speech with Kell-Neverh", In RECEN? ADVANCES IN SPEECH UNDERSTANDING SYSTEMS, NATO ASIS, Springer Verlag. (MER 75) Mermolsteln, P., (1975), "Automatic segmentation of speech into Syllabic Units", JASA, Vol. S8, Bab-883. J 11901 , meatination de 1 a Durce intrinseque

(NOE 88) Noeth E (1988), "Prosodic teatures in German Speech" in RECEN ADVANCES IN SPEECH UNDERSTANDING SYSTEMS, NATO ASIS, SPringer verlag.

IOMA 73) O'Malley, M.H., Kloker, D.R., Dara-Abrams B., (1973), "Recover ing Parentheses from Spoken Algebrail Expressions", TEEE Trans. On Audio and Electroacoustics, Vol.

intisation de la Prosodie Pour PIE 86) Pleraccini, R., (1986), "Lexical stress and Speech Recognition",

(VAI 76) Vaissibre, J., (1976), Mutomatic Procedure for Segmenting Continuous Speech into prosodic Words, in French", Recherches Acoust iques, Crench

(VAI 77) Vaisaitre, J. (1977), "Premiers Essais d'Ut1lisation de 1a Durte pour 1a segmentation en Mots dans un Systeme de Reconnalssan

Journees d'Etudes sur la Parole, Aix-en-Provence, 345-352. 82a) Valssiere, J.. (1982), A suprasegment Speech Recognition System: Reducing the Number of Lexical Hypotheses and Datecting the Main soundary ions, vol. VII, 109-125.

(VAI B2b) Vaissidere, J.. (2982), "Utillsation des Parametres Suprasegmentaux on Reconnaissance Aut omatique de la Paz
tation on Phonemos", in (DIC 82), 123-140.
(VAI 83) Vaissiere, J.. (1983), Language-Independent Prosodlc reaturea", in PROSODY: MODELS NDD MEASUREMENTS, (A.Cut ler \& R. Ladd, editors), Tokyo Springer-Verlag, pp. 53-66

(VAI 84) Vaissiere, J. (1984), "PROSEIDON: Automatic Detection of Prosody Cues in Continuous Speech", Proceedings of the XIIIth Journdes d"Etudes sur la Parole", Bruxelles, 28-30 May, 189-190

(VAI B6) Valssiore, J., PUTER SPEECH PROCESSING, F. Fallside and W.A. Moods, oditors, Prentice

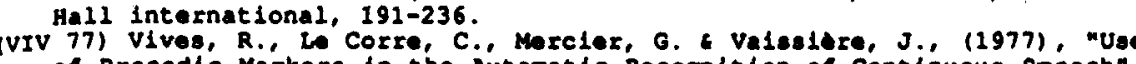
of Prosodic Markers in the Automatic Recognition of Continuous Speech", en-Provence, 353-363.

(MaI 86) Maibol, A., (1986), "Recognition of Lexical stress in a continuous Spoech Understanding systea. A Pattern Rocognition Approsch", ICASSP

(WAI 87) Waibe1, A., (1987), "Prosodic knowledge Sources for Word Hypothes(wIN 75) Wingfield, A., (1975), "Acoust ic Redundancy" , ICASSP-87, 856-859. Time-compressed Speech", J. Speech HearIng Res., 18, 96-104. 